\title{
The Impact of Labor Market Regulations
}

\author{
Lyn Squire and Sethaput Suthiwart-Narueput
}

\begin{abstract}
This article investigates the impact of labor market regulations in a setting with incomplete compliance. It takes as its starting point the limited evidence regarding the distortionary costs of labor market regulations and argues that there may exist natural limits to the efficiency losses engendered by such regulations. The article reviews some stylized facts regarding labor market behavior, presents an analytical model that may explain such behavior, and provides a checklist for assessing the distortionary impact of regulations such as minimum wages.
\end{abstract}

Does labor market regulation in developing countries result in significant efficiency losses? In his survey paper, Freeman (1993: 139) expressed surprise that "Studies designed to support the distortionist view of labor markets in developing countries failed to make a stronger empirical case than they did."

There are several possible explanations for this result. First, the regulations may not be binding at the market equilibrium. Second, even if the regulations are binding, the relevant elasticities of supply and demand may be so low that the impact of the regulations on efficiency is small. And third, even if the regulations are binding and the elasticities are sizable, compliance may be low. On this point, Freeman (1993: 128) notes that "If extensive unemployment results, the minimum will often be unenforceable because both workers and employers will have incentives to collude to avoid the law and save jobs." In this article we focus on the third reason and argue that the following proposition holds: the likelihood of noncompliance will be greatest when the regulations are binding and the relevant elasticities are sizable. That is, if the distortionary costs of regulations are not rendered insignificant by the first two reasons, then the returns to noncompliance will be high and, other things being equal, employers will either evade or avoid the regulations, thereby minimizing their impact on efficiency.

Lyn Squire and Sethaput Suthiwart-Narueput are with the Policy Research Department at the World Bank. This article was originally prepared as a background paper for World Development Report 1995: Workers in an Integrating World. The authors gratefully acknowledge Ahmed Galal, Dipak Mazumdar, Branko Milanovic, Martin Rama, participants at a World Development Report seminar at the World Bank, three anonymous referees for comments, and Marcel Fratzscher for research assistance. The authors also thank Martin Rama, Klaus Schmidt-Hebbel, Luis Servén, and various officials at labor departments in Ecuador, Egypt, Kenya, and the United States for their help in a small survey of labor enforcement practices.

1997 The International Bank for Reconstruction and Development / THE WORLD BANK 
The argument obviously depends on a comparison of the returns to noncompliance (increased profits) relative to its costs (penalties or transaction costs) and presumes some form of profit-maximizing behavior subject to tight budget constraints. This might be a fair approximation of the private sector reality of developing countries, but in many instances public sector enterprises have been an important form of industrial organization. It can be argued that such enterprises are not concerned exclusively with profit maximization and frequently face very soft budget constraints. This suggests that public enterprises may be more willing than private enterprises to conform with profit-reducing regulations. We argue that the very same factors that lead to this outcome may also imply that compliance does not have the efficiency costs that arise in the case of private producers. Therefore, we explore the proposition that, although public enterprises are more likely to comply with labor market regulations, public enterprise compliance may actually reduce efficiency losses. Taken together, the two propositions suggest that natural limits exist to the efficiency losses engendered by labor market regulations.

For concreteness of discussion, we focus on minimum-wage legislation. The approach, however, could be easily recast to deal with other forms of intervention (hiring and firing regulations, for example). We review some empirical evidence and stylized facts regarding labor market behavior and then provide an analytical model that may explain such behavior. The goal is to provide a framework and checklist for assessing the distortionary impact of labor market regulations such as minimum wages and for selecting case studies for future in-depth research. This approach is consistent with Freeman's (1993: 139) conclusion that "More can be learned from detailed case studies than from cross-country time-series regression with weak data."

Section I outlines recent trends in minimum wages throughout the developing world. Section II explores the proposition that noncompliance is greatest when the regulations are binding, and provides empirical evidence and stylized facts regarding noncompliance. Section III derives an analytical explanation for the behavior of firms in the private sector and establishes the conditions under which the distortionary impact is likely to be high. Section IV describes the situation in the public enterprise sector, which is modeled in section V. The final section presents a checklist for assessing the likely distortionary impact of minimumwage legislation.

\section{RECENT TRENDS}

The view that real minimum wages consistently rose in the 1970 s and consistently fell in the 1980s is not fully borne out by the available data (see tables 1 and 2). The conventional view is most accurate in the case of Latin America. Although it is difficult to observe any trend in the 1970 s, real minimum wages did fall throughout most of the region in the 1980 s, in some cases by substantial amounts-by about half to one-third in most countries. 
A similar picture might emerge for Africa if more data were available. As it is, the evidence for Africa reveals a mixed picture in both the 1970s and $1980 \mathrm{~s}$, and even where there are declines in the $1980 \mathrm{~s}$, the fall is much less than in Latin America-only about 20 percent. A relatively stable situation

Table 1. Real Minimum Wages, Selected Countries, 1970-90

(index, 1980=100)

\begin{tabular}{|c|c|c|c|c|c|}
\hline Country & 1970 & 1975 & 1980 & 1985 & 1990 \\
\hline \multicolumn{6}{|l|}{ Latin America } \\
\hline Argentina & 182 & 185 & 100 & 113 & 50 \\
\hline Bolivia & 99 & 130 & - & 33 & 31 \\
\hline Brazil & 90 & 94 & 100 & 84 & 51 \\
\hline Chile & 64 & 61 & 100 & 63 & 88 \\
\hline Colombia & 77 & 78 & 100 & 108 & 107 \\
\hline Costa Rica & 88 & 77 & 100 & 112 & 121 \\
\hline Ecuador & 49 & 51 & 100 & 61 & 44 \\
\hline Guatemala & 118 & 96 & 100 & 85 & 61 \\
\hline Honduras & - & 122 & 100 & 90 & 74 \\
\hline Mexico & 91 & 91 & 100 & 67 & 42 \\
\hline Nicaragua & - & 119 & 100 & 47 & - \\
\hline Panama & 119 & 116 & 100 & 101 & 99 \\
\hline Paraguay & 151 & 140 & 100 & - & - \\
\hline Peru & 118 & 115 & 100 & 54 & 21 \\
\hline Uruguay & 124 & 143 & 100 & 94 & 69 \\
\hline Venezuela & - & 85 & 100 & 95 & 65 \\
\hline \multicolumn{6}{|l|}{ Asia } \\
\hline Philippines & 101 & 65 & 100 & 82 & 83 \\
\hline Sri Lanka & 73 & 84 & 100 & 94 & - \\
\hline Thailand & - & 84 & 100 & 117 & 117 \\
\hline \multicolumn{6}{|l|}{ Africa } \\
\hline Algeria & 56 & 69 & 100 & - & - \\
\hline Benin & - & 143 & 100 & 91 & - \\
\hline Botswana & - & 85 & 100 & 113 & - \\
\hline Burkina Faso & 79 & 87 & 100 & 87 & 101 \\
\hline Congo & - & 157 & 100 & 96 & - \\
\hline Côte d'Ivoire & 104 & 114 & 100 & 84 & - \\
\hline Gabon & 90 & 107 & 100 & 90 & 84 \\
\hline Ghana & 415 & 509 & 100 & 144 & 114 \\
\hline Kenya & 119 & 121 & 100 & 68 & - \\
\hline Malawi & - & 119 & 100 & 120 & - \\
\hline Mauritius & - & - & 100 & 104 & - \\
\hline Morocco & - & 98 & 100 & 118 & 132 \\
\hline Niger & - & 87 & 100 & 70 & 81 \\
\hline Senegal & 99 & 111 & 100 & 78 & 78 \\
\hline Togo & 143 & 131 & 100 & 80 & 80 \\
\hline Tunisia & - & 77 & 100 & 110 & 100 \\
\hline Zaire & 805 & 599 & 100 & 164 & - \\
\hline
\end{tabular}

-Not available.

Source: Anker, Butare, and Marinakis (1992). 
Table 2. Percentage Change in Real Average and Minimum Wages, Selected Countries, 1980 s

\begin{tabular}{lccc}
\hline Country & $\begin{array}{c}\text { Average wage } \\
\text { (1) }\end{array}$ & $\begin{array}{c}\text { Minimum wage } \\
(2)\end{array}$ & $\begin{array}{c}\text { Difference } \\
(1)-(2)\end{array}$ \\
\hline Latin America (1980-87) & & & \\
Argentina & -0.5 & 20.8 & -21.3 \\
Brazil & 2.3 & -35.3 & 37.6 \\
Chile & -6.0 & -42.4 & 36.4 \\
Colombia & 19.3 & 13.0 & 6.3 \\
Costa Rica & -7.7 & 18.1 & -25.8 \\
Guatemala & -22.7 & -38.9 & 16.2 \\
Honduras & -8.0 & -16.0 & 8.0 \\
Mexico & -43.3 & -43.2 & 8.4 \\
Paraguay & -1.9 & 20.0 & -21.9 \\
Peru & -10.8 & -39.2 & 28.4 \\
Uruguay & 14.0 & 10.9 & 3.1 \\
Africa (1980-86) & & & \\
Burundi & & & \\
Kenya & 4.7 & -3.5 & 10.7 \\
Malawi & 40.6 & 54.6 & -14.0 \\
Mauritius & 3.7 & -24.0 & 27.7 \\
Asia (1980-88) & -22.8 & -41.2 & 18.4 \\
Sri Lanka & & & \\
Thailand & -11.4 & -6.2 & -5.2 \\
\hline
\end{tabular}

Source: ILO (1990).

emerges for the three Asian countries: movements up and down stay within 20 percent of the 1980 base.

\section{The Private Sector and Enforcement strategy}

The impact of minimum-wage legislation is limited because of incomplete compliance by private firms. For the purposes of this article, we treat noncompliance as payment below the minimum wage. As discussed later, it can take two forms: outright evasion or (legal) avoidance, for example through the use of temporary contracts. Impact is defined as a change in the demand for labor. An increase in a perfectly enforced and binding minimum wage would lead unambiguously to a fall in the demand for labor. This textbook proposition has come under question in the U.S. context (see Card and Krueger 1995). With incomplete compliance, the demand for labor could fall, remain constant, or even increase. This section identifies the circumstances in which these different outcomes will hold.

\section{Noncompliance in the Private Sector}

Noncompliance occurs in a variety of countries and is significant even among industrial countries with the proper apparatus-established bookkeeping and 
reporting procedures, for example-for regulatory enforcement. Analyzing 1973 data for the United States, Ashenfelter and Smith (1979) find that only 64 percent of the persons who would have earned less than the minimum in the absence of legislation were paid in compliance with it. For California in 1989, Card (1991) finds that noncompliance was as high as 46 percent among workers directly affected by the increase in the minimum wage. Noncompliance in the entire population, however, was less than 2 percent.

Turning to developing countries, household survey data for Mexico reveal that, in 1988, 16 percent of all full-time male workers in the informal sector and as many as 66 percent of female workers in various sectors were paid below the minimum wage (Bell 1994). These percentages are significant given the large size of the informal sector: only 18.2 percent of all enterprises in 1988 were estimated to have been fully meeting all legal requirements regarding inscription and contributions (Standing and Tokman 1991). In Colombia in 1983, 4.7 percent of even large manufacturing enterprises did not comply with the minimumwage legislation (Bell 1994). In Morocco more than 50 percent of the firms paid their unskilled workers less than the minimum wage in 1986 (Harrison 1993). In Sub-Saharan Africa the extent of noncompliance is even more striking. A recent survey of 300 informal sector firms in Niger revealed that 293 did not comply with minimum-wage regulations; in Swaziland, 242 out of 290 failed to comply (Morrisson 1993).

The pattern of noncompliance. Because the observed extent of noncompliance represents a joint response to both the costs of compliance and the costs of enforcement, it is difficult to disentangle the two. In certain instances, however, it may be possible to identify the two effects separately through careful interpretation of time-series and cross-sectional data coupled with some assumptions.

Several cases indicate that noncompliance increases with the costs of compliance for the firm. In California noncompliance affected 31 percent of the persons directly affected by the minimum-wage legislation in 1987 and 46 percent in 1989 , when the minimum wage increased from $\$ 3.35$ to $\$ 4.25$ per hour (Card 1991). Because the intensity of enforcement is not likely to have changed significantly in such a short period of time and median wages rose only 7.6 percent, much of the increase in noncompliance was likely caused by the increased costs of complying with the higher minimum wage.

In Puerto Rico, noncompliance (in the entire population of workers) rose from around 20 percent in 1979 to 35 percent in 1983, when the minimum wage increased from $\$ 2.56$ to $\$ 3.35$. Noncompliance in Puerto Rico is likely to have been significantly higher, because only 64 percent of the workers were covered by the minimum-wage legislation and the workers not covered were probably employed in the informal sector and small enterprises (see Freeman and Freeman 1991). Again, assuming that the intensity of enforcement remained more or less the same, this suggests that noncompliance increased because the costs of compliance to the firm increased. 
Conversely, noncompliance in Mexico decreased along with the costs of noncompliance when real minimum wages decreased during the 1980s. The ratio of the minimum to average wage for blue-collar workers fell from 0.42 to 0.34 from 1984 to 1989 , while the percentage of large manufacturing firms paying average wages below the minimum similarly fell from 3.0 to 1.9 percent (Bell 1994). If the structure of enforcement did not change markedly, this would indicate that noncompliance fell along with the decrease in the costs of complying with minimum-wage regulations.

Given the increase in the number of firms over time, we would expect compliance to fall unless the enforcement budget is increased commensurately. In general, cross-country comparisons are problematic because the structure of enforcement could differ significantly across countries. However, because the enforcement systems in both California and Puerto Rico are under the U.S. Department of Labor and are therefore likely to be similar, the significantly higher ratio of noncompliance in Puerto Rico could be attributed largely to the relative costs of compliance: the ratio of minimum to average earnings was 63 percent in Puerto Rico but only 34 percent in the United States as a whole in 1987.

The pattern of noncompliance is also consistent with the observation that noncompliance varies with the ease of enforcement. Although it is unclear how enforcement costs vary over time, there are sound reasons for believing that they vary across the population of firms and workers at a given point in time. For example, because enforcement costs (on both a per firm as well as a per worker basis) are likely to be higher for small firms operating in the informal sector, it is not surprising that noncompliance is also significantly higher in this group. The percentage of full-time male workers with wages below the minimum was more than 16 percent in the informal sector, but less than 3 percent in the formal sector in Mexico (Bell 1994). In Morocco, wage histograms show that noncompliance in enterprises with fewer than twenty employees is significantly higher than in larger enterprises (Harrison 1993).

Of course, this pattern is also consistent with higher compliance costs for the firm. Smaller, informal sector firms typically hire more unskilled than skilled labor, more younger than older workers, and more women than men relative to larger firms in the formal sector. To the extent that labor markets are segmented, these smaller, informal sector firms could face higher efficiency losses from compliance because the average wage for these demographic groups is lower and their elasticity of labor demand is higher. It is therefore not surprising that compliance is noticeably lower for these demographic groups. In California in 1987, 67 percent of persons who earned less than the minimum wage were twenty-four years of age or younger, 37 percent were Hispanics, and 67 percent were female (Card 1991). In Mexico, despite a decline in real minimum wages, noncompliance remained significantly high in the informal sector, in the south, for women, and for people with little or no education. Regarding region, noncompliance in the south of 
Mexico was 29 percent for full-time workers in the informal sector but only 8.2 percent for the same group in Mexico City. Regarding education, noncompliance for full-time male workers in the informal sector with no education was 26.5 percent but only 2 percent for those in the same sector with sixteen or more years of education (Bell 1994). Wage histograms for Morocco also show that noncompliance is significantly higher for unskilled female workers than for men (Harrison 1993).

Although cross-country comparisons do not allow the effects of compliance and enforcement costs to be distinguished, they can nonetheless be revealing. Differences in noncompliance between countries in Sub-Saharan Africa and other countries are very striking. In contrast to the noncompliance figures for Niger and Swaziland cited above, only 49 out of 503 firms in Thailand, and 29 out of 269 in Ecuador, were in noncompliance with minimum-wage regulations (Morrisson 1993). Minimum wages have considerably less bite in Mexico than in Colombia, which indicates that the incentives for noncompliance are much higher in the latter. Annual industrial surveys for manufacturing firms in both countries show that in Mexico only 10 percent of the firms paid average bluecollar wages less than 1.5 times the minimum wage compared with 29 percent of Colombian firms in 1986 (Bell 1994).

Legal noncompliance. Widespread noncompliance is not surprising in view of the numerous means for legally avoiding such regulations. Many countries exempt teenagers, apprentices, workers in training, and part-time workers from the minimum-wage legislation. In Morocco, for instance, firms are allowed to pay as little as 50 and 80 percent of the minimum wage for fourteento fifteen-year-olds and seventeen- to eighteen-year-olds, respectively; this regulation provides significant incentives for legal avoidance. The renewal of temporary contracts is a common means of avoiding payment of the minimum wage in Mexico. This form of avoidance is particularly widespread in large-scale industries and among such government-controlled enterprises as the petroleum monopoly, probably because outright evasion is more difficult and riskier in these sectors and for these enterprises (see Standing and Tokman 1991).

The survey of informal sector firms conducted by Morrisson (1993) shows that even when firms formally comply with minimum-wage regulations de jure, they may avoid them de facto by hiring "false apprentices" or failing to pay overtime. In Algeria, Jamaica, and Thailand, compliance with the minimumwage legislation was significantly higher than compliance with regulations regarding the payment of overtime. In Jamaica, while 58 percent of firms complied with minimum wages, only 21 percent complied with the payment of overtime. Similarly, in Algeria and Thailand, 54 and 77 percent, respectively, complied with minimum wages but only 46 and 64 percent, respectively, complied with the payment of overtime. (These percentages are only of firms that responded to Morrisson's survey.) 


\section{Enforcement Strategy}

The patterns of compliance described represent outcomes that reflect both the behavior of private firms and the regulator's strategy of enforcement. The analysis of Ashenfelter and Smith (1979) illustrates this point well. Their analytical model predicts that firms employing low-wage workers and for which wage changes produce large employment adjustments have the greatest incentives to violate the law. But they argue that this incentive is more than fully offset by the higher probability of government detection that results from the government's enforcement strategy.

Although theoretical models of enforcement with formally specified regulator behavior do exist (for example, Garvie and Keeler 1993; Polinsky and Shavell 1990), they may be based on a view of regulator behavior that has little to do with actual enforcement practice. The literature on this is unfortunately rather sparse. However, it appears not only that actual regulator strategies may diverge from those predicted on the basis of statutory directives but also that the ability of regulators to execute their strategies could be quite limited.

Of particular interest are the studies on the enforcement of affirmative action regulation among federal contractors by the U.S. Office of Federal Contract Compliance Program (OFCCP). Under Executive Order 11246, federal contractors agree "to take affirmative action to ensure that applicants are employed and employees are treated during employment without regard to their race, color, religion, sex, or national origin" (cited in Leonard 1990: 48). Given this mandate, it would be reasonable to expect the OFCCP to concentrate its compliance reviews on establishments with a relatively small proportion of females and black males. However, Heckman and Wolpin (1976: 547) examine the incidence of compliance reviews among 1,185 Chicago-area establishments and discover "no evidence of a systematic government policy for reviewing contractor firms." The probability of review was not affected by the size of the establishment or by the level of or change in minority employment.

In a later study of compliance reviews of 7,369 defense contractor establishments for 1975-79, Leonard (1985: 378) finds that "the greater the proportion of female or minority male, the more likely is a review" (italics added). On paper, the OFCCP does have formal targeting systems that select establishments with a low relative proportion of minorities or females for review. However, as Leonard notes (1985: 374),

In practice, targeting at the OFCCP has for the most part been done on an ad hoc decentralized basis, with field officers exercising considerable discretion. Field officers tend to be evaluated on fulfilling goals for compliance reviews, rather than on successfully bringing discriminators to heel. . . The fastest way to fill a production goal for compliance reviews is to review firms with good records and good behavior.

Not only is the strategy of the regulator far from obvious, but its ability to execute its strategy effectively is also unclear. Preliminary results from our small, 
informal survey of the departments of labor in several countries indicate that the actual impact of enforcement activities is severely circumscribed by inadequate staff resources, limited budgets, and small penalties.

Limited inspection resources. Even in the case of the U.S. Department of Labor, only 800 federal wage-and-hour inspectors nationwide cover about 2.6 million employers. In Ecuador the Inspección del Trabajo has only twenty-six inspectors in the Quito office, which covers about half of the country's labor force. In Bangladesh the 1991 annual report of the Ministry of Labor and Manpower Inspectorate mentions only two investigations under the Minimum Wages Act (World Bank 1994).

Where inspection resources are limited, investigations tend to be initiated in response to complaints rather than to be random. ${ }^{1}$ In the United States nearly three-quarters of the compliance actions taken in 1992 and 1993 were driven by complaints. In Ecuador inspections are typically only carried out when requested by workers or, more often, by unions. In Morocco unions are similarly a major channel for transmitting complaints regarding violations of labor regulations. By contrast, in Egypt, which has 1,600 inspectors and more plentiful inspection resources, random inspections are the norm, and those driven by complaints are few.

Small explicit penalties and weak enforcement. Statutory penalties are quite low. In the United States most minimum-wage violations involve only paying back the difference in wages owed to the workers. In 1989 Congress instituted a civil monetary penalty for repeated or willful (that is, falsified records with an intent to conceal) minimum-wage and overtime violations. Employees can also bring cases of violations of the Fair Labor Standards Act directly to court without any involvement by the U.S. Department of Labor, in which case they may get double the amount of losses plus court fees. Labor law violations in Kenya typically lead to advice of correction rather than penalties. The Kenya Department of Labor typically employs the following procedure when detecting noncompliance: provide advice of correction for a maximum of one to three times for a period of two to four weeks and take the firm to court if the violation is not corrected. Penalties require court sentences and are in any case quite low: current maximum fines are capped at $\$ 75$ per offense (not per worker).

Enforcement of penalties is even more limited. In Bangladesh, although 411 violations were detected in 1988, 518 in 1989, and 610 in 1990, there were only 13 prosecutions in 1990 and 3 in 1991 (World Bank 1994). In Kenya only 60 court convictions (and 212 prosecutions) resulted from the 26,625 inspections

1. There is also the danger of engaging in mostly surface enforcement (that is, conducting more desk reviews and fewer in-depth audits). After 1980 the OFCCP doubled the number of compliance reviews despite reductions in staffing and the real budget. Not surprisingly, "Fewer administrative complaints were filed, back-pay awards were phased out, and the already rare penalty of debarment became an endangered species" (Leonard 1990: 58). 
carried out by the Department of Labor in 1993. In Ecuador, in spite of a "rush" by firms to regularize their arrears following a reform of the Labor Code in 1991 , the total amount of fines collected in fiscal 1993-94 was only around $\$ 5,000$. In many cases, there is little direct financial incentive to collect penalties. In Kenya fines collected are transferred back to the Treasury. In Egypt, although funds go back to the Ministry of Manpower and Employment, the collection of penalties levied is the responsibility of the Ministry of Justice and the Ministry of the Interior.

\section{The Model for the Private Sector}

The analysis presented in this section captures the interaction between firms and the regulator by assuming that firms face a known probability of inspection. This approach is followed for two reasons. First, there is no empirically established view regarding the regulator's objective function. Second, alternative objective functions-such as minimizing evasion or maximizing net financial returns from inspection-lead to little change in the analysis other than the replacement of a known probability of inspection with the distribution of enforcement costs by type of firm. In the following, we present a simple model in which the probability of inspection increases with firm size. ${ }^{2}$

Some firms may fail to pay the minimum wage by legal avoidance, and others may engage in outright evasion. Firms following the former routefor example, by subcontracting or hiring only temporary or young workers to whom the legislation does not apply-can be expected to incur various training or transaction costs that have to be incorporated in any assessment of the welfare effects of the legislation. In our setup, switching to temporary workers to avoid paying the minimum wage is different than switching from labor to capital because of minimum-wage regulations. Switching from permanent to temporary workers involves paying below the minimum wage (what we have termed "avoidance"), while switching from labor to capital involves paying the (higher) minimum wage (what we term "compliance"). Firms following the outright evasion route may not incur real resource costs but will of course face possible punitive action if they are investigated. The model allows for both possibilities.

\section{Firm Options}

Assume a size distribution of profit-maximizing firms differentiated by a productivity parameter $\theta_{i}$. The model treats a single-production technology. This has two important implications. First, it does not capture the possibility that labor market legislation influences the choice of technology. Although potentially important, it is not obvious that labor market legislation is by

2. We also ran a version of the model in which the probability of inspection is constant with respect to firm size. It yielded a different partern of firm compliance, but the main qualitative results of the analysis carried through. 
itself likely to be a main determinant of technology. And second, with a single-production technology, differences in firm size stem only from differences in productivity. In reality, of course, firms differ in size because of differences in technology as well as in productivity (that is, unproductive firms making petrochemicals tend to be larger than productive ones making garments).

With these comments as background, assume that $\theta$, has a cumulative distribution $G(\theta)$ with support $(\underline{\theta}, \bar{\theta})$. The government introduces a minimum wage into this setting. Firms have three options. First, pay the minimum. Second, legally avoid the minimum through various costly actions such as subcontracting or hiring part-time workers. And third, evade. The formulation for the payoff under evasion reflects beginning-of-period inspection and the fact that the model deals with an instant in time. During that instant, a potential evader either evades for the entire instant or is caught on suspicion, as it were, and both complies and pays the penalty for the entire instant. The expected payoffs $E \pi_{i}$ for each option are:

$$
E \pi_{i}=\left\{\begin{array}{l}
\pi\left(\theta_{i}, \bar{w}\right) ; \text { if comply } \\
(1-\beta) \pi\left(\theta_{i}, w\right)+\beta\left(\pi\left(\theta_{i}, \bar{w}\right)-\Gamma\right) ; \text { if evade } \\
\pi\left(\theta_{i}, w\right)-A ; \text { if avoid }
\end{array}\right.
$$

where

$$
\pi\left(\theta_{i}, w\right)=\max _{K, L} p \theta_{i} F(K, L)-w L-r K
$$

and $w$ is the market wage, $\bar{w}$ is the minimum wage, $\beta$ is the probability of inspection, $\Gamma$ is the penalty, and $A$ is the fixed cost associated with avoidance. ${ }^{3}$ $F(K, L)$ is homogeneous of degree less than 1 in its arguments because of the presence of some fixed factor. We assume throughout that $\bar{w}>w$ and define units in such a way that $w$ and $\bar{w}$ incorporate nonwage benefits as well. As mentioned above, we assume the probability of inspection to be higher for larger firms and let $\beta$ be strictly increasing in $\theta_{i}$. Although $\theta_{i}$ itself is directly unobservable, in this simplified setting there is a one-to-one correspondence between firm size and $\theta_{i}$. We can therefore represent an inspection policy that targets larger firms as a function $\beta$ that is increasing in $\theta_{1}$.

3. There are several implications in allowing the penalty, $\Gamma$, and cost of legal avoidance, $A$, to be functions of employment. Consider, for example, $A(L)=a L$ and $\Gamma(L)=\gamma L$. In this case, there is a knifeedge situation depending on parameter values. If $\bar{w}-w>a$, then firms prefer to avoid rather than comply, but if $\bar{w}-w<a$, then firms prefer to comply rather than avoid. Because this holds for any given value of $\theta_{\text {, }}$, we only observe evading and complying or avoiding firms, but not all three. In the case of $\Gamma(L)$, the penalty could be imposed on the number of workers employed when the firm evades. Labor demand under evasion becomes $L\left(\theta_{i}, w+\beta \gamma\right)$. Inequality 3 , which indicates when firms prefer to evade rather than comply, becomes $\pi\left(\theta_{1}, w+\beta \gamma-\pi\left(\theta_{i}, \bar{w}\right)>\beta \gamma L\left(\theta_{i}, w+\beta \gamma\right) /(1-\beta)\right.$. If $w+\beta \gamma=\bar{w}$, then $\beta \gamma L\left(\theta_{i}, \bar{w}\right)>\pi\left(\theta_{i}, w+\beta \gamma-\pi\left(\theta_{i}, \bar{w}\right)=0\right.$, and firms prefer to comply rather than evade. Because this is true for any $\theta_{1}$, if $\gamma>[(\bar{w}-w) / \beta]$, we would never observe any evading firms. 
From equation 1, firms will evade rather than comply if

$$
\Delta \pi \equiv \pi\left(\theta_{i}, w\right)-\pi\left(\theta_{i}, \bar{w}\right)>\frac{\beta\left(\theta_{i}\right) \Gamma}{1-\beta\left(\theta_{i}\right)} .
$$

Firms will comply rather than avoid if

$$
\pi\left(\theta_{i}, w\right)-\pi\left(\theta_{i}, \bar{w}\right)<A
$$

We know from equation 2 and the envelope theorem that the derivative of the left side of the above inequalities with respect to $\theta_{i}$ is positive for $\bar{w}>w$. This is not altogether surprising because higher $\theta$ firms will be larger and will obtain greater surplus from hiring at a lower wage than will smaller firms. We consider the situation when $\beta$ increases in $\theta_{i}$ sufficiently sharply that the right side of inequality 3 intersects the left side from below as depicted in figure 1 . We also separately considered the case when the right side of inequality 3 intersects the left side from above; for example, when $\beta\left(\theta_{i}\right)=\beta$. This yields a different pattern of firm compliance in which lower $\theta_{i}$ firms comply, intermediate $\theta_{i}$ firms evade, and larger $\theta$, firms avoid. The main qualitative results, however, carry through whether the intersection is from above or below.

We denote the values of $\theta_{i}$ that satisfy inequalities 3 and 4 with equality as $\theta^{c}$ and $\theta^{A}$, respectively. Given the direction of inequalities 3 and 4 , it follows

Figure 1. Pattern of Firm Compliance

$\Delta \pi ; \beta(\theta) \Gamma /[1-\beta(\theta)] ; A$

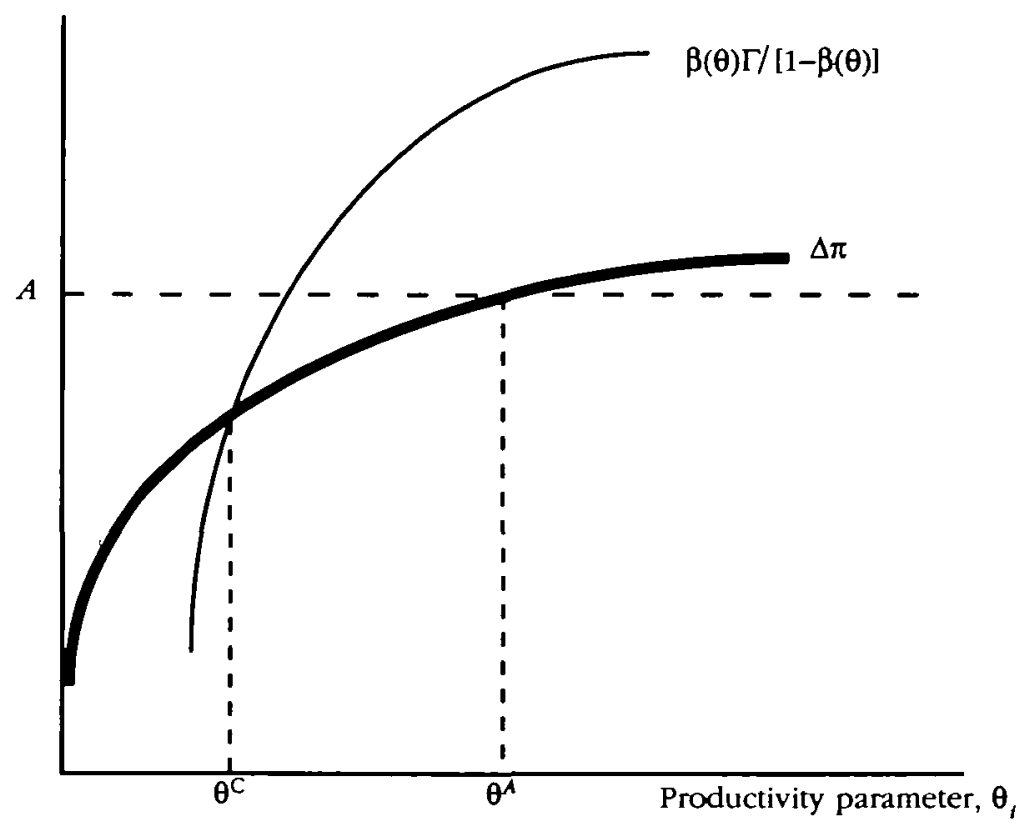


that we only observe firms (an interval of $\theta_{i}$ ) seeking to comply if $\theta^{c}<\theta^{A}$ or

$$
A>\frac{\beta\left(\theta^{C}\right) \Gamma}{1-\beta\left(\theta^{C}\right)} .
$$

If the transaction cost of avoidance $A$ is not sufficiently large, there will be no compliance, because firms either evade or avoid. Firms will evade if $\Delta \pi\left(\theta_{i}\right)<A /\left[\beta\left(\theta_{1}\right)-\Gamma\right]$; and they will avoid otherwise. For the remainder of the article, we assume that inequality 5 holds because it is the more interesting case.

We now consider the pattern of compliance. For those firms with $\theta_{i}<\theta^{c}$, $A>\Delta \pi\left(\theta_{i}\right)>\beta\left(\theta_{i}\right) \Gamma /\left[1-\beta\left(\theta_{i}\right)\right]$. The first inequality implies that these firms prefer to comply rather than to avoid, while the second implies that they prefer to evade rather than to comply. Firms in this range therefore evade. For those firms with $\theta_{i} \in\left(\theta^{C}, \theta^{A}\right), A>\Delta \pi\left(\theta_{i}\right)$ still, but $\beta\left(\theta_{i}\right) \Gamma /\left[1-\beta\left(\theta_{i}\right)\right]>$ $\Delta \pi\left(\theta_{t}\right)$. The first inequality again implies that firms prefer to comply rather than to avoid, but the second now implies that they prefer to comply rather than to evade. Firms in this second range therefore comply. Lastly, for firms with $\theta_{i}>\theta^{A}, \beta\left(\theta_{i}\right) \Gamma /\left[1-\beta\left(\theta_{1}\right)\right]>\Delta \pi\left(\theta_{i}\right)$ still, but $\Delta \pi\left(\theta_{i}\right)>A$. The first inequality implies that firms prefer to comply rather than to evade, while the second now implies that they prefer to avoid rather than to comply. Firms in this last range avoid. We therefore get the result that smaller, less productive firms with $\theta_{1} \leq \theta^{c}$ evade, those with $\theta^{C}<\theta_{i} \leq \theta^{A}$ comply, and larger, more productive firms with $\theta_{i}>\theta^{A}$ avoid.

\section{Regulator Options}

Inequality 3 shows that the regulator can influence the degree of evasion through two variables: the probability of inspection and the severity of the penalty. Other things being equal, the regulator can minimize noncompliance by increasing these two variables. The effective penalty may reflect not just explicit statutory penalties (which as indicated above may be quite minimal) but also any reputation or other cost associated with being found in violation of labor regulations. The regulator can also influence the extent of avoidance through the precision and comprehensiveness of the relevant labor legislation that would work through the fixed transaction cost, $A$ (see inequality 4). As loopholes in the legislation are progressively closed, the transaction costs associated with avoidance are likely to increase.

Taking stock of these results, we conclude the following. First, increases in the probability of inspection $\beta$ lower $\theta^{c}$. The proportion of firms complying increases, while the proportion of those evading decreases. Second, increases in the per firm penalty, $\Gamma$, have a similar effect. Third, increases in the specificity of the labor legislation raise $\theta^{\wedge}$. The proportion of firms avoiding decreases, and the proportion of firms complying increases. 
Although the regulator has sufficient instruments to eliminate evasion and avoidance, the empirical evidence makes clear that regulators choose not to do this. The regulator's choice reflects both the objectives of the regulator and the costs of enforcement. Depending on the objectives, the real costs associated with avoidance may also influence the regulator's view of the relative merits of evasion and avoidance.

\section{Labor Market Outcomes}

Does the likelihood of noncompliance increase as the (binding) minimumwage increases and as the elasticity of labor demand increases? First, we establish that this is indeed so. Second, we derive the circumstances in which an increase in a binding minimum wage results in increased demand for labor. And third, we discuss the implications of these results for the efficiency losses arising from labor market regulation.

Consider the left side of inequality 3 , denoted $\Delta \pi$, in figure 1 . An increase in $\bar{w}$ shifts up $\Delta \pi$ and therefore increases $\theta^{c}$. To determine the impact of changes in elasticity, we conduct a second-order Taylor series expansion on $\Delta \pi$ around $\left(w, \theta^{c}\right)$. With some manipulation, this yields

$$
L\left(w, \theta^{c}\right)(w-w)-\frac{1}{2} \frac{L\left(w, \theta^{c}\right)}{w}(w-w)^{2} e
$$

where $e<0$ is labor elasticity. Because expression 6 increases with the absolute value of $e$, an increase in the absolute value of $e$ shifts up $\Delta \pi$ and increases $\theta^{c}$ while decreasing $\theta^{A}$, which decreases the proportion of complying firms. Thus, the likelihood of noncompliance does increase with both the minimum wage and the elasticity of demand for labor, which makes intuitive sense. Both of these factors increase the costs of the minimum wage and therefore encourage more noncompliance.

We now examine the effect of an increase in the minimum wage on labor demand. We conduct a partial equilibrium analysis and take the market wage as given. This could occur, for example, in a small formal sector in which the wage level is determined outside the market, although in a more general setting, changes in the level of the minimum wage could affect the market wage, $w$. Total labor demand $L^{D}($.$) is given by$

$$
L^{D}(.) \equiv-\int_{\underline{\theta}}^{\theta^{c}} \pi_{\omega}\left(\theta_{\imath}, w\right) \mathrm{d} G(\theta) \mathrm{d} \theta-\int_{\theta^{c}}^{\theta^{c}} \pi_{\omega}\left(\theta_{1}, \bar{w}\right) \mathrm{d} G(\theta) \mathrm{d} \theta-\int_{\theta^{\wedge}}^{\bar{\theta}} \pi_{\omega}\left(\theta_{\imath}, w\right) \mathrm{d} G(\theta) \mathrm{d} \theta
$$

where the three integrals correspond to labor demand from evading, complying, and avoiding firms, respectively. After some manipulation and simplification, the effect on labor demand of increasing $\bar{w}$ is given by

$$
\theta_{\bar{w}}^{C}\left[L\left(\theta^{C}, w\right)-L\left(\theta^{C}, \bar{w}\right)\right]-\theta \frac{A}{\bar{w}}\left[L\left(\theta^{\wedge}, w\right)-L\left(\theta^{\wedge}, \bar{w}\right)\right]+\int_{\theta^{c}}^{\theta^{\wedge}} \frac{\partial L\left(\theta_{1}, \bar{w}\right)}{\partial \bar{w}} \mathrm{~d} G \mathrm{~d} \theta
$$

where $\theta_{\bar{w}}^{i}$ is the partial of $\theta^{j}$ with respect to $\bar{w}$. 
The result fits with intuition. Recall that $\theta^{c}$ increases (and $\theta^{A}$ decreases) with $\bar{w}$ and that $L\left(\theta^{j}, w\right)-L\left(\theta^{j}, \bar{w}\right)$ is positive for $\bar{w}>w$. Each of the first two products in expression 8 is therefore positive and represents the increase in the proportion of noncomplying firms $\left(\theta_{\varpi v}^{\prime}\right)$ multiplied by the increase in labor demand as (each) firm switchs from compliance to noncompliance. The integral is negative and captures the decrease in labor demand from complying firms-those in the interval $\left(\theta^{C}, \theta^{A}\right)$-caused by higher minimum wages. Because the integral term is a second-order effect compared to the two product terms, expression 8 could well be positive, and an increase in the minimum wage could increase labor demand as a result of lower compliance. However, this depends on the size of the gap between the minimum and market wages. The expression is more likely to be positive the greater the gap between minimum and market wages, because $L\left(\theta^{\prime}, w\right)-L\left(\theta^{\prime}, \bar{w}\right)$ is larger and the proportion of complying firms is smaller. If the minimum wage is close to the market wage, however, then the proportion of complying firms is large, and the expression is likely to be negative because the effect of decreased labor demand on compliers will dominate. We therefore have a Laffer-curve type of relationship between the minimum wage and labor demand caused by incomplete compliance. This relationship contrasts markedly with the outcome in a world of complete compliance, where raising the minimum wage unambiguously lowers labor demand and increases unemployment.

What are the implications of these results for the efficiency losses usually associated with labor regulations? There are at least three effects of an increase in minimum wages, assuming that enforcement costs remain fixed: an increase in the distortion for complying firms, a reduction in the costs of distortions as firms switch from being compliers to being noncompliers, and an increase in transaction costs as firms switch from being evaders to being avoiders. The first two effects arise immediately from expression 8 , and the third derives from expression 4 defined with equality. As with labor demand, these results imply that efficiency losses could increase, stay constant, or fall as the minimum wage is increased. Moreover, the likelihood of a reduction in efficiency losses will increase with the size of the existing distortion, which, as we have seen, is one of the factors determining the likelihood of an increase in labor demand. This analysis points, therefore, to the existence of natural limits on the magnitude of efficiency losses.

These results have two implications for policy. First, although the efficiency losses from compliance may arguably be justified on redistributive grounds because compliance results in a transfer to workers, governments are unlikely to be willing to incur the costs (enforcement costs and efficiency losses) associated with full compliance. (Compliance does not necessarily lead to a more equitable outcome; although rent is transferred to employed workers, the number of employed workers is reduced.) There is therefore likely to be an optimal degree of noncompliance. Second, because there is no redistributive transfer to workers under avoidance relative to evasion, and yet there are real resource costs associ- 
ated with the former, it may be preferable to reduce legal avoidance rather than evasion. Another factor is that the avoiding firms are larger than the evading ones in our setup and will therefore incur higher distortionary costs from compliance. Tightening legislation will also make it costlier for those that continue to avoid. The policy response should be to focus on tightening legislation in an effort to cut back on legal avoidance rather than to increase inspections and penalties per se. This result holds even if real costs are associated with evasion, as long as those costs are less than those incurred when avoiding.

The results also bear on the recent debate in the literature regarding the impact of minimum-wage legislation on employment in the United States. Card and Krueger (1995) summarize an array of statistical evidence and conclude that increases in the minimum wage have not reduced employment and may even have increased it. Their empirical evidence is hotly disputed. We are not in a position to judge the empirical validity of their conclusion. We note, however, that our results and, in particular, the change in compliance following an increase in the minimum wage could explain what they claim to observe. Moreover, our explanation does not require invoking the untested assumption of monopsony power or informational imperfections; rather it rests on a standard competitive model with incomplete compliance. Although our model may have more relevance for developing countries where enforcement is especially weak, in some of the "natural experiments" considered by Card and Krueger, noncompliance did increase as predicted by our model.

\section{PUBLIC ENTERPRISES}

In this section we examine the impact of labor market regulations on public enterprises. We assume that public enterprises operate according to a different objective function and effectively face a looser budget constraint than private enterprises.

\section{Large and Growing Employment and Wage Bills}

Public enterprise employment and wage bills have often grown very rapidly in developing countries and have remained large. After a strong increase in public enterprise employment during the 1960s and 1970s, the share of public enterprise employment in total employment remained relatively constant at between 5 and 6 percent worldwide between 1978 and 1991 (see table 3). But regional differences in public enterprise employment remain large. Between 1986 and 1991 the share of public enterprises in total employment in Africa was 18.1 percent, significantly larger than the corresponding share in Latin America (3.7 percent) and Asia ( 4.7 percent). This share was as high as 46.4 percent in Niger, 45.3 percent in Senegal, and 37.2 percent in Zambia (Galal 1994).

Even in those countries where real wages in the public sector have declined, these reductions have often been more than offset by an increase in public sector employment. In her study on public sector pay and employment policies, Nunberg 
Table 3. Weighted Average Share of Public Enterprises in Employment, Selected Countries, 1978-91

(percent)

\begin{tabular}{lccc}
\hline Region & $1978-85$ & $1986-91$ & $1978-91$ \\
\hline Africa & 17.55 & 18.07 & 17.77 \\
Asia & 4.92 & 4.68 & 4.82 \\
Latin America and the Caribbean & 4.07 & 3.67 & 3.90 \\
World & 5.55 & 5.28 & 5.43 \\
\hline
\end{tabular}

Note: Only a subset of countries within each region was used for deriving world averages. The Latın American and Caribbean regional average excludes Argentina, Brazil, Ecuador, Grenada, and Trinidad and Tobago. The African regional average excludes Burundi, Côte d'lvoire, Egypt, Kenya, Malawı, Niger, Senegal, Seychelles, and Tanzania. The Asian regional average excludes Indonesia, Myanmar, Sri Lanka, and Vietnam. Three-year moving average estimates were used to complete our time series in case of missing values when deriving regional averages. Regional weighted averages were obtained using GDP in current U.S. dollars as weights.

Source: Galal (1994).

(1988) found an excessive wage bill to be a major problem for the majority of countries where the World Bank pursues government pay and employment interventions. In Egypt, for example, the wage bill grew from 22 percent of government expenditures in the mid-1970s to 33 percent in the late 1980s (Banerji and Sabot 1993).

\section{Noneconomic Objectives}

Public enterprises are often assigned employment goals, are required to act as model employers, and may be required to serve as employers of last resort. Although governments seek to protect real wages for workers, when this is not possible they may attempt to protect employment by cutting spending on nonwage items, compressing the wage structure, and cutting real wages.

Public enterprises act as model employers and seek to protect workers against declines in the wage rate. In Morocco overall productivity in formal manufacturing fell between 1985 and 1990 . However, although the productivity decline was larger in the public sector, real wages in the public sector rose 0.4 percent a year, while falling 2.3 percent in the private sector, even though they were higher than real wages in the private sector to begin with (Harrison 1993). In Bangladesh five out of seven public enterprises sampled had increases in average labor costs that outpaced increases in productivity. For a public enterprise producing steel billets and plates, average labor costs increased 55 percent between 1985 and 1992, but the value of output per worker actually fell 18.6 percent (World Bank 1994).

When operating under tight financial constraints, however, governments may seek to protect employment by reducing spending on material. The ratio of wage to nonwage public expenditures has been increasing in many countries with fiscal constraints, which indicates growing distortions and imbalances in the input mix of public sector production. In Liberia, for example, the wage bill in relation to revenues increased from 36 percent in 1977 to 66 percent in 1981 (Lindauer 1988). 
The government may also compress the wage structure to protect employment of lower paid workers, often reducing wages for their more skilled employees below those offered for equivalent skills in the private sector. Lindauer, Meesook, and Suebsaeng (1987) find significant salary compression for a number of African countries. In Ethiopia, for example, the lowest real salaries in the public sector fell 37 percent between 1975 and 1985, but real wages fell nearly 70 percent for the highest salaries (ILO 1990). In Zambia the salary ratio between the highest- and lowest-rank civil service employee fell from 19.2 percent in 1970 to 6.9 percent in 1983 (see Lindauer 1988). As a consequence, the wage difference for skilled labor between the private and public sector has become particularly high. In Thailand in 1982 the differential for top positions in both sectors was as high as 350 percent (Lindauer 1988).

Because there is a negative tradeoff between employment and the wage bill when governments are financially constrained, governments may resort to reducing real wages to protect employment. There has been a considerable reduction in real wages in Africa. Public sector wages for the lowest salary groups fell 45 percent between 1975 and 1985 , whereas the highest salaries in the public sector fell more than 60 percent on average during the same period. In Somalia, for instance, the real value of the lowest salary and of the highest salary in the civil service in 1985 was only 5.2 and 4.0 percent of their 1975 value, respectively (ILO 1990).

Public enterprises may also be required to act as employers of last resort. To reduce unemployment, governments often guarantee jobs and provide funds to hire graduates, which make these employees costless for public enterprises. In Egypt such a policy has resulted in significant overstaffing (Gelb, Knight, and Sabot 1991). Similar employment policies are found in Central African Republic, Guinea, Mali, Senegal, Sudan, and Togo, where university graduates are automatically hired by public institutions.

Collectively, these factors have resulted in considerable overstaffing among public enterprises in many countries. A comparison of public and private manufacturing enterprises in Turkey has shown the existence of significant labor and capital surplus among public manufacturing enterprises: the ratio of public to private labor and of capital inputs per unit of output was 1.97 and 1.66, respectively (Gelb, Knight, and Sabot 1991: 1187). Overstaffing in the public sector in Egypt was as high as 40 percent in 1976. In part, this reflected the provision of funds to hire graduates, which made these employees costless for public enterprises (Gelb, Knight, and Sabot 1991). As a consequence, whereas employment in Egypt's private sector grew only 7.8 percent, it rose 24.5 percent in public enterprises during 1976-86 (Banerji and Sabot 1993). Overstaffing in particular sectors is estimated to be as high as 93 percent in the spinning industry of Egypt, 54 percent in the transport sector of Ghana, 91 percent in the Bombay port of India, and 40 percent in the railway sector of Turkey (Banerji and Sabot 1993). 


\section{Negative Profits}

Public enterprises are frequently not expected to make a profit. Noneconomic objectives such as employment or equity appear to outweigh efficiency considerations, making public enterprises a significant burden on the government budget. Gross operating profits of public enterprises in nearly all developing countries were significantly negative between 1978 and 1991 (Galal 1994). Negative gross operating profits were between 2 and 3 percent of gross domestic product (GDP) in Africa and Asia for the period 1978-91. There was little or no improvement during the 1980s in Asia or Africa. Only in Latin America did gross operating profits improve significantly between 1978 and 1991, from negative gross operating profits of more than 1 percent of GDP between 1978 and 1985 to a small surplus between 1986 and 1991.

\section{The Model for Public Enterprises}

In contrast to the pure profit-maximizing behavior of the private sector, public enterprises are assumed to maximize a modified measure of profits:

$$
\pi\left(\theta_{i} ; \lambda w\right)=\max _{L} p \theta_{i} F(K, L)-\lambda w L-r K .
$$

Here $\lambda$ is an exogenously given measure reflecting the net influence of a concern with the wage bill (employment generation and wages), on the one hand, and recognition of the need for fiscal discipline, on the other. If $\lambda$ equals 1 , the government has no special employment objective or the fiscal constraint dominates or both. In this case, public enterprises are required to maximize profits. With a more pressing national employment objective and a more relaxed fiscal situation, $\lambda$ may approach 0 , at which point labor becomes costless to the enterprise. This implies overstaffing and a drain on the central budget. In exceptional circumstances, $\lambda$ could be negative.

Alternative specifications of the objective function of public enterprises are possible and would yield different implications. Public enterprises may have an employment objective (to alleviate unemployment) or a high wage objective. Our specification reflects both these considerations as well as the stylized fact of high wage bills.

\section{Compliance with Minimum-Wage Laws}

Unlike private firms, the choices open to public enterprises with respect to labor market regulations may be more severely circumscribed. We can distinguish three different institutional arrangements. First, public enterprises may have little control over their wage and employment decisions. There may be a central wage-fixing and wage-paying body that applies to all public enterprises. In this case, public enterprises will comply with minimum-wage laws because they have no choice. Or there may be a virtual prohibition on firing workers in public enterprises, in which case increases in the minimum wage will reduce 
profits or increase losses. Second, each public enterprise may have the capacity to choose between the minimum wage and the market wage, but the effective penalty or probability of inspection may be higher for public enterprises. If it is easier for government regulatory authorities to ensure payment of fines by public than by private firms, for example, the effective penalty will be higher for public firms. Recourse to nonpecuniary measures-for example, firing of public managers-could also result in higher effective penalties for public than for private firms. Alternatively, the probability of inspection $\beta$ could differ. Labor may be more aware of its rights in a public enterprise or have a higher expectation that its grievances will receive attention. If so, the frequency of complaints, and hence of inspections, may be greater for public enterprises. These factors will increase the likelihood of compliance.

A third possibility is that the determination of wage payments is left to the enterprise as before but that the effective penalty and probability of inspection are the same for public and private firms. Because this case offers the most immediate comparison with private firms, we pursue it here to see whether public enterprises are more likely to comply than their private counterparts. If the answer is "yes," then we know that public enterprises are more likely to comply than private firms for all institutional arrangements because public enterprise compliance will be lowest for the particular one under study.

To examine this issue, we note that the general form of the results for public enterprises is identical to that for private firms. In particular, we can derive two inequalities similar to inequalities 3 and 4 to determine whether public enterprises will comply, evade, or avoid. The only difference is that the left side of these inequalities will reflect the modified objective function:

$$
\pi\left(\theta_{i} ; \lambda w\right)-\pi\left(\theta_{i} ; \lambda \bar{w}\right) .
$$

In both inequalities the right side is the same for public as for private firms, and so, as before, we will observe evaders among public enterprises if inequality 5 holds. In the following, we assume that it does hold.

These similarities (on the right side) and differences (on the left side) allow us to shed light on whether public enterprises are more or less likely to comply than private firms. To see this, note that the relevant margin is the compliance/evasion one and from equation 9 , for $\lambda=1$, the private and public firm problems are identical. Therefore, if expression 10 is decreasing in $\lambda$, then we know that public enterprises-for which in general $\lambda<1$ - have less incentive to evade and more incentive to comply than private firms. This result holds, all things being equal, obviously, in particular, for a given $\theta_{i}$.

Let $L\left(w, \theta_{i} ; \lambda\right)$ solve equation 9 . Then, expression 10 , which reflects the incentive to evade, can be written as

$$
-\lambda[w L(w, .)-\bar{w} L(\bar{w}, .)]+p \theta_{i}\{F[\bar{K}, L(w, .)]-F[\bar{K}, L(\bar{w}, .)]\} .
$$

To assess how the incentive to evade changes with the degree of fiscal discipline and the concern with employment, differentiate expression 11 with respect to $\lambda$. 
Using the envelope theorem, this yields $\bar{w} L(\bar{w},)-.w L(w,$.$) . With inelastic labor$ demand, this expression is positive, and the incentive to evade decreases as the social concern with employment increases, fiscal discipline is relaxed and $\lambda$ is reduced, or both occur. With elastic labor demand, the expression is negative, and the incentive to evade increases as the social concern with employment increases, fiscal discipline is relaxed and $\lambda$ is reduced, or both occur. Thus, public enterprises are more likely to comply with minimum-wage legislation than their private sector counterparts in situations where the demand for labor is inelastic. This makes intuitive sense. For any positive $\lambda$, an inelastic demand curve implies that compliance results in a higher wage bill, which in turn lowers the objective function for both private and public firms. From equation 9 , however, any given increase in the wage bill will lower the value of the objective function of public enterprises less than that for private firms because $\lambda<1$, which reflects the fact that the wage bill is less "costly" in the public enterprise objective function because of relaxed fiscal discipline. Empirical estimates of the wage elasticity of labor demand in manufacturing typically produce absolute values well below 1 (see, for example, the estimates provided in Bell 1994: tables 7 and 8, or in Revenga 1994: table 10). These values indicate that in general public enterprises are indeed more likely than private firms to comply with labor market regulations even when confronted with the same regulatory environment.

\section{Public Enterprise Compliance and Efficiency}

If public enterprises are more likely than private firms to comply with minimum-wage legislation, then are efficiency losses greater for public enterprises? Here we show that the factor that leads to the result on compliance also has implications for the efficiency impact. To see this, consider the relationship between public enterprise compliance and labor demand. The first-order condition for a complying public enterprise is given simply by $\theta_{t} p F_{L}(K, L)=\lambda \bar{w}$, while that for an equivalent noncomplying private firm is given by $\theta_{p} p F_{L}(K, L)=w$. Denote the latter solution as $L^{*}$. The complying public enterprise therefore hires less labor than $L^{*}$ if $\lambda \geq w / \bar{w}$ (and hires more labor if $\lambda<w / \bar{w}$ ). ${ }^{4}$ This outcome reflects the fact that $\lambda$ and $w$ exert opposing forces on labor demand- $-\lambda$ increases labor demand, but $w$ reduces it.

Evaluated purely from the standpoint of productive efficiency, it appears reasonable to assume that efficiency losses increase the farther away $L$ is from $L^{*}$. Evaluating this from a welfare standpoint requires an assessment of the alternative public enterprise objective function. It follows that the introduction of a minimum wage could reduce efficiency losses for complying public enterprises as they move away from a situation of excess labor demand and closer to the free-market equilibrium. In effect, public enterprises have too many workers, so a minimum wage that cuts employment is beneficial. Thus, $\lambda<w / \bar{w}$ is suffi-

4. Since $\bar{w}>w>0, w / \bar{w}^{\prime} \in(0,1)$ while $\lambda \in[1,-\infty)$, we know that there exists a critical value $\lambda^{*}=w / \bar{w}$. 
cient but not necessary for compliance by public enterprises to reduce efficiency losses. ${ }^{5}$ By contrast, in private firms, compliance increases efficiency losses. This contrast between public and private firms has noteworthy implications for policy. It suggests that from the standpoint of improving compliance, it is preferable to focus on public than on private enterprises because with public enterprises there are less likely to be increased efficiency losses that offset the gains in equity from greater compliance.

\section{Analyzing Labor Market Regulations: A Checklist}

Based on the preceding analysis, the following checklist provides a means for heuristically evaluating the likely distortionary impact of minimum-wage regulations. Where the preliminary evaluation suggests significant distortionary costs, further research and analysis are needed.

- Check whether the legislated minimum wage is potentially binding. As empirical studies demonstrate, minimum wages are not likely to have significant employment or other effects if they do not "bite." One helpful exercise would be to consider the relationship of the minimum wage to the wage distribution. Wage histograms that spike at or near the minimum wage rather than significantly to the right indicate situations where the minimum wages have more bite. Such histograms for Morocco, differentiated by firm size, indicate, for example, that minimum wages are considerably less binding for larger than for smaller firms. Similarly, the fact that only 6 and 24 percent of firms had average wages below 1.5 and 2 times the minimum, respectively, in Mexico, but that 27 and 71 percent did so in Colombia indicates that minimum wages potentially had more bite in Colombia (data are for 1989 for Mexico and 1987 for Colombia, from Bell 1994). Although this check will give a preliminary indication, in practice there may be several complications. For example, several legislated minimum wages may correspond to different sectors or classes of firms. Furthermore, because the total return to labor includes both wage and nonwage elements, simple comparisons of average to legislated minimum wages may not capture the true extent to which the minimum wages are binding.

- If the legislated minimum wage is potentially effective, check the extent of noncompliance. To arrive at a quick assessment of the extent of noncompliance, it would be useful to interview the relevant staff in the country's department of labor. Their assessment of the situation could be supplemented with data on the size of the enforcement budget, the number of inspectors and prosecutions, and the severity of fines. It would also be

5. Public enterprise compliance does not always reduce efficiency losses because such firms could end up hiring so few workers that efficiency losses are greater under compliance than under noncompliance. Recall that for $\lambda=1$ public enterprise behavior is identical to private firm behavior. Because compliance results in efficiency losses for private firms, public enterprise compliance at $\lambda=1$ results in efficiency losses. 
useful to check the relevant legislation to establish the scope for easy and legal avoidance through such means as use of temporary workers, apprentices, or subcontracting. As a cross-check, a small survey of selected enterprises in different segments (private/public, formal/informal) would be desirable. In addition to government administrative capacity, strong labor unions and judicial systems may also play an important role in determining the effectiveness of enforcement. In Ecuador and Morocco, for example, unions reportedly act as important channels for transmitting complaints regarding violations of labor regulations. In the United States, many plaintiffs take cases of violations directly to court without involving the Department of Labor.

- If the legislated minimum wage is binding and enforced, check the relative size of the public and private sectors. If the private sector predominates, then the evidence already compiled provides a basis for concluding that distortionary costs are potentially significant and that further analysis is required. If, instead, the public sector predominates, one more test is required because in this case the efficiency impact depends on the net strength of the employment objective and the fiscal constraint. One indication of the net strength of these factors is the extent of net financial flows from government to public enterprises. High figures could indicate a looser fiscal constraint. For example, as a proportion of GDP in 1978-91, these figures were 2.5 percent for Argentina, but -12.1 percent for Chile, and 16.6 percent for Algeria, but -6 percent for Egypt (Galal 1994). In the event that public enterprises appear to operate like profit-maximizing private firms, then, as with private firms, the evidence would point to potentially significant efficiency losses and would call for further investigation.

To conclude, we return to the opening quote from Freeman. In our checklist we have set out three conditions that have to be fulfilled before we can expect to see significant distortions associated with legislated minimum wages. It is our presumption that in many developing countries these conditions are unlikely to be fulfilled. If this is true, then Freeman's surprise at the lack of evidence regarding the distortionary costs of minimum wages is explained, at least as far as broad, cross-country comparisons are concerned. Such costs could, however, still be significant in some countries at some times.

\section{REFERENCES}

The word "processed" describes informally reproduced works that may not be commonly available through library systems.

Anker, Richard, Theopiste Butare, and Andre Marinakis. 1992. "Minimum Wages in Developing Countries: Trends and Determinants." International Labour Office, Geneva. Processed.

Ashenfelter, Orley, and Robert Smith. 1979. "Compliance with the Minimum Wage Law." Journal of Political Economy 87(2):333-50. 
Banerji, Arup, and Richard H. Sabot. 1993. "Wage Distortions, Overmanning, and Reform in Developing Country Public Enterprises." Policy Research Department, World Bank, Washington, D.C. Processed.

Bell, Linda. 1994. "The Impact of Minimum Wages in Mexico and Colombia." Policy Research Working Paper 1514. World Bank, Washington, D.C. Processed.

Card, David. 1991. “Do Minimum Wages Reduce Employment? A Case Study of California, 1978-89.” NBER Working Paper 3710. National Bureau of Economic Research, Cambridge, Mass. Processed.

Card, David, and Alan B. Krueger. 1995. Myth and Measurement: The New Economics of the Minimum Wage. Princeton, N.J.: Princeton University Press.

Freeman, Richard B. 1993. "Labor Market Institutions and Policies: Help or Hindrance to Economic Development?" Proceedings of the World Bank Annual Conference on Development Economics 1992. Washington, D.C.: World Bank.

Freeman, Richard B., and Alida Castillo Freeman. 1991. "Minimum Wages in Puerto Rico: Textbook Case of a Wage Floor?” NBeR Working Paper 3759. National Bureau of Economic Research, Cambridge, Mass. Processed.

Galal, Ahmed. 1994. "Public Enterprises in Developing Countries after a Decade of Divestiture." Policy Research Department, World Bank, Washington, D.C. Processed.

Garvie, Devon, and Andrew Keeler. 1993. "Incomplete Enforcement with Endogenous Regulatory Choice.” Discussion Paper 873. Institute for Economic Research, Queens University, Kingston, Canada. Processed.

Gelb, Alan, John B. Knight, and Richard Sabot. 1991. "Public Sector Employment, Rent Seeking, and Economic Growth.” Economic Journal 101(September):1186-99.

Harrison, Ann. 1993. “Morocco Private Sector Assessment: The Labor Market, 1993.” Policy Research Department, World Bank, Washington, D.C. Processed.

Heckman, James J., and Kenneth I. Wolpin. 1976. "Does the Contract Compliance Program Work? An Analysis of Chicago Data." Industrial and Labor Relations Review 29(4, July):544-64.

ILO (International Labour Organisation). 1990. "Wages, Labour Costs, and Their Impact on Adjustment, Employment, and Growth." Geneva. Processed.

Leonard, Jonathan S. 1985. "Affirmative Action as Earnings Redistribution: The Targeting of Compliance Reviews." Journal of Labor Economics 3(3):47-63.

. 1990. "The Impact of Affirmative Action Regulation and Equal Employment Law on Black Employment." Journal of Economic Perspectives 4(4):47-63.

Lindauer, David L. 1988. "Government Pay and Employment Policies and Government Performance in Developing Economies.” Policy Research Working Paper 42. Policy Research Department, World Bank, Washington, D.C. Processed.

Lindauer, David, Oey Meesook, and Parita Astra Suebsaeng. 1987. "Government Wage Policy in Africa: Some Findings and Policy Issues." Country Policy Department Discussion Paper 8624. Country Policy Department, World Bank, Washington, D.C. Processed.

Morrisson, Christian. 1993. "Le problème des bas salaires et du salaire minimum dans les pays en développement." Organisation for Economic Co-operation and Development, Paris. Processed. 
Nunberg, Barbara. 1988. "Public Sector Pay and Employment Reform." Working Paper Series 113. Country Economics Department, World Bank, Washington, D.C. Processed.

Polinsky, A. Mitchell, and Steven Shavell. 1990. "Enforcement Costs and the Optimal Magnitude and Probability of Fines." NBER Working Paper 3429. National Bureau of Economic Research, Cambridge, Mass. Processed.

Revenga, Ana. 1994. “Employment and Wage Effects of Trade Liberalization: The Case of Mexican Manufacturing.” Policy Research Working Paper 1524. Policy Research Department, World Bank, Washington, D.C. Processed.

Standing, Guy, and Victor E. Tokman. 1991. "Towards Social Adjustment: Labour Market Issues in Structural Adjustment.” International Labour Office, Geneva. Processed.

World Bank. 1994. “Bangladesh: Labor Market Policies for Higher Employment.” South Asia Country Department, Washington, D.C. Processed. 